Revisão / Review

\title{
Causas genéticas de deficiência de ferro
}

\section{Genetic causes for iron deficiency}

Sara Teresinha O. Saad

\section{Introdução}

As causas genéticas de deficiência de ferro, real ou funcional, ocorrem por defeitos em muitas proteínas envolvidas na absorção e metabolismo de ferro. $\mathrm{O}$ ferro funcional não está disponível para os eritroblastos sintetizarem hemoglobina, ou o eritroblasto é incapaz de captar ferro da circulação, mas o ferro está acumulado em tecidos ou nas mitocôndrias. Nos últimos anos, várias descobertas, principalmente oriundas de descrições em humanos ou de modelos animais, ajudaram a elucidar a implicação dos componentes do metabolismo do ferro na deficiência de ferro hereditária, que afetam desde a absorção intestinal até sua inclusão final no heme. Deste modo, neste capítulo foram resumidos aspectos práticos das anemias hereditárias por deficiência de ferro causadas por atransferrinemia hereditária, aceruloplasminemia congênita, mutação no transportador divalente de metal (DMT-1/Nramp2), mutação na serina-protease ligada à membrana tipo 6 (TMPRSS6) ou matriptase-2 e também mutações com perda da função da ferroportina. Em vista de se tratar de um guia para hematologistas, vimos aqui uma oportunidade de abordar também as anemias sideroblásticas congênitas e as porfirias associadas à anemia, tais como a porfiria eritropoética congênita e a protoporfiria eritropoética, pois nestas, de alguma forma, ocorre defeito na utilização do ferro. Foram então resumidos aspectos práticos da anemia sideroblástica ligada ao X por mutações na sintase tipo 2 do ácido aminolevulínico (ALAS2), por mutações no transportador mitocondrial eritroide específico (SCL25A38), por mutações na glutaredoxina e a anemia sideroblástica ligada ao X com ataxia. Além disso, foram tratadas causas de anemia microcítica hipocrômica, com deficiência de ferro funcional, ainda não descritas em humanos, mas cujos modelos animais estão bem estudados, tais como defeitos na hefestina, no

Hematologista. Professora Titular de Hematologia da Faculdade de Ciências Médicas da Universidade Estadual de Campinas (Unicamp) Campinas-SP

Centro de Hematologia e Hemoterapia da Universidade Estadual de Campinas (Unicamp) - Campinas-SP.

Correspondência: Sara Teresinha Olalla Saad

Hemocentro - Unicamp

Rua Carlos Chagas, 480 - Cidade Universitária Zeferino Vaz

13083-970 - Campinas-SP - Brasil

Tel.: (55 19) 3551-8734; Fax (55 19) 3289-1089

E-mail: sara@unicamp.br

Doi: 10.1590/S1516-84842010005000067 
receptor 1 de transferrina, na proteína reguladora de ferro tipo 2 ( IRP2), no antígeno epitelial transmembrana de próstata tipo 3 ( STEAP3) e na SEC1511. A descoberta de novos genes envolvidos nestas deficiências, tais como GRX5, DMT1 ou TMPRSS6, somados aos genes identificados em camundongos sugere que estas condições possam ser mais frequentes do que se supunha inicialmente. Como o diagnóstico molecular destas anemias é de fácil acesso, a dificuldade está na identificação do gene candidato adequado para ser sequenciado nestes pacientes.

Neste capítulo descreveremos sucintamente causas genéticas de carência de ferro para a síntese de hemoglobina, que cursa então com anemia microcítica e hipocrômica. Ressalto que estas são alterações raras, com poucas descrições na literatura. Em alguns casos, o ferro funcional não está disponível para os eritroblastos sintetizarem hemoglobina, ou o eritroblasto é incapaz de captar ferro da circulação, mas o ferro está acumulado em tecidos ou nas mitocôndrias.

\section{Anemias hereditárias por deficiência de ferro}

\section{Atransferrinemia hereditária}

Também conhecida como hipotransferrinemia congênita, é uma doença muito rara, caracterizada por anemia microcítica hipocrômica e sobrecarga de ferro. As bases moleculares desta doença foram descritas apenas em quatro pacientes. Além dos sintomas de anemia, os pacientes também apresentam maior suscetibilidade a infecções. Em vista da transferrina liberar ferro para os eritroblastos e para outros tecidos, a atransferrinemia resulta em síntese reduzida de hemoglobina. Secundariamente, há marcante absorção de ferro que, no plasma, está na forma não ligada a transferrina e, portanto, causa grave sobrecarga de ferro para fígado, pâncreas e coração e outras glândulas. A medula óssea é desprovida de ferro tanto em macrófagos como em eritroblastos.

A herança é, provavelmente, autossômica recessiva, e o diagnóstico pode ser feito através da constatação de grande redução na capacidade de ligação do ferro com a transferrina e redução ou ausência de transferrina plasmática, medida por imunodifusão radial ou imunoeletroforese.

Correção da anemia e da sobrecarga de ferro tem sido obtida com infusão mensal de plasma fresco congelado ou de apotransferrina, que é seguida por aumento de reticulócitos após 10 a 14 dias da infusão. Com esse tratamento, é possível rapidamente recuperar os níveis de hemoglobina e a realização de flebotomia para tratamento da sobrecarga de ferro. Há autores que recomendam a infusão de $500 \mathrm{~mL}$ de plasma fresco congelado seguido de flebotomia de $500 \mathrm{~mL}$, mensalmente. ${ }^{1-4}$

\section{Aceruloplasminemia congênita}

Esta doença é autossômica recessiva, rara, caracterizada por anemia, sobrecarga de ferro e neurodegeneração. A doença é causada por ausência de ceruloplasmina, que catalisa a oxidação de ferro ferroso para férrico, processo necessário para a ligação do ferro à tranferrina. Os pacientes desenvolvem diabetes, degeneração retinina, ataxia e demência. A anemia é leve a moderada, com diminuição de ferro sérico e elevados níveis de ferritina. Há deposição de ferro no fígado e gânglios da base do encéfalo. A doença tem sido descrita principalmente em japoneses. $O$ diagnóstico é feito pela redução de cobre sérico e ausência de ceruloplasmina sérica. A doença exibe algumas semelhanças com a Doença de Wilson. A terapia recomendada para esta doença é quelação de ferro. ${ }^{1,5-6}$

\section{Mutação no transportador divalente de metal (DMT-1/Nramp2)}

A proteína codificada por este gene é encontrada nas membranas plasmáticas e nos endossomas de células do duodeno e tecidos periféricos. Atua na captação de ferro pelo intestino e aquisição de ferro pelos tecidos periféricos. Deste modo, mutações neste gene causam diminuição da utilização de ferro pelos eritroblastos, embora os estoques de ferro hepáticos estejam aumentados. Até o momento, três pacientes foram relatados na literatura com mutação neste gene. Além da anemia, há elevada saturação de transferrina e aumento de ferritina. Aparentemente há relação do fenótipo com o genótipo. Deste modo, paciente com mutação que modifica a função sem alterar a expressão da proteína mostra anemia mais leve do que aquele com defeito, que altera a quantidade da proteína.

Os pacientes descritos até o momento tiveram resposta à administração de eritropoetina; e este tratamento não modifica o VCM e HCM das hemácias, sugerindo não haver melhora na captação de ferro pelos eritroblastos, mas parece reduzir a apoptose dos mesmos, resultando em melhora da anemia. Os níveis de ferritina sérica reduzem drasticamente com a administração de eritropoetina, mas, em um paciente, o tratamento por quatro anos não preveniu o acúmulo de ferro hepático. ${ }^{1,7-11}$

\section{Mutação na serina-protease ligada à membrana tipo 6 (TMPRSS6) ou matriptase-2}

Esta proteína cliva a hemojuvelina, um regulador da hepcidina na membrana plasmática. A função da proteína foi descrita a partir da sua descoberta em camundongos naturalmente deficientes de ferro e anemia microcítica e hipocrômica. Estes animais exibem absorção ineficiente de ferro e alopecia regional que são corrigidas pela suplementação de ferro parenteral. Ao contrário da anemia ferropriva típica, em que os níveis de hepcidina sérica estão muito reduzidos, nestes animais ela está aumentada.

Pacientes com mutação neste gene apresentam anemia hipocrômica e microcítica, com níveis de ferro sérico muito diminuídos e hepcidina sérica normal ou elevada. Os pacientes são refratários ao tratamento com ferro oral e têm 
resposta parcial ao ferro parenteral, provavelmente pela dificuldade de captação e processamento do ferro pelos macrófagos, antes da sua utilização pelos eritroblastos. ${ }^{1,12-14}$

\section{Mutações com perda da função da ferroportina}

Alguns pacientes com mutação na ferroportina mostram leve anemia microcítica hipocrômica. Observou-se que, nesses casos, as mutações ocorrem em regiões da proteína que fazem o transporte de ferro do enterócito e do macrófago para a circulação e, deste modo, há comprometimento da absorção de ferro e sequestro de ferro nos macrófagos. As mutações, portanto, levam à perda da função da ferroportina, que é justamente a de exportar o ferro das células. Além da anemia microcítica hipocrômica, estes pacientes têm sobrecarga de ferro nos macrófagos e aumento da ferritina sérica, sem aumento da saturação de transferrina. Os pacientes são refratários ao ferro oral e podem responder parcialmente á administração parenteral. ${ }^{15-17}$

\section{Anemias sideroblásticas congênitas}

As anemias sideroblásticas congênitas compreendem um grupo de doenças caracterizadas por população variável de hemácias hipocrômicas microcíticas no sangue periférico e sideroblastos em anel na medula óssea. Estes sideroblastos anormais apresentam ferro retido na mitocôndria, que dá o aspecto de anel perinuclear à coloração de Perls dos eritroblastos, e a anemia microcítica hipocrômica reflete um defeito na síntese do heme mitocondrial. São doenças raras e que ocorrem por mutações em várias proteínas mitocondriais ou citosólicas dos eritroblastos.

Anemia sideroblástica ligada ao X por mutações na sintase tipo 2 do ácido aminolevulínico (ALAS2)

Esta é a forma mais frequente das anemias sideroblásticas congênitas, podendo atingir cerca de $40 \%$ dos casos diagnosticados. Os hemizigotos têm anemia microcítica hipocrômica com sobrecarga de ferro. A maioria das mutações afetam a ligação da enzima com piridoxal fosfato, etapa fundamental para a formação de ALA utilizada na síntese do heme. Estes casos são responsivos à piridoxina, que pode ser usada na dose de $50 \mathrm{mg}$ a $200 \mathrm{mg} /$ dia. Mutações da enzima que cursa com redução dos seus níveis ou impede a sua interação com outras proteínas não respondem à piridoxina. ${ }^{18-22}$

\section{Mutações no transportador mitocondrial eritroide específico (SCL25A38)}

Este proteína transporta ácido delta aminolevulínico pela membrana mitocondrial e participa da síntese do heme. A herança é autossômica recessiva e cursa com grave anemia hipocrômica microcítica e sobrecarga de ferro precoce. É provavelmente a segunda causa mais frequente de anemia sideroblástica congênita, atingindo cerca de $15 \%$ dos casos. ${ }^{18-20}$

\section{Anemia sideroblástica ligada ao X com ataxia}

Esta é uma síndrome muito rara que decorre do defeito do transportador de ABCB7(ATP binding cassette transporter), cuja herança é ligada ao cromossomo X. Este transportador está presente na membrana mitocondrial e participa da biogênese e transporte dos cluster de ferroenxofre da mitocôndria para o citosol. Os pacientes apresentam leve anemia microcítica hipocrômica, aumento dos níveis de protoporfirina IX livre eritrocitária e interrupção da maturação dos clusters de ferro-enxofre citosólicos. Esses clusters, no citoplasma, são essenciais para a ativação de proteínas envolvidas no metabolismo do ferro.

Quelantes de ferro podem melhorar a neuropatia, provavelmente porque esta decorre de lesão mitocondrial pela toxicidade do ferro nas células nervosas. ${ }^{18-20,23}$

\section{Mutação na glutaredoxina}

Esta proteína compõe o maquinário que junta os clusters de ferro-enxofre na mitocôndria. A perda da função desta proteína induz à maior ativação de proteínas reguladoras de ferro, falsamente refletindo deficiência de ferro para genes alvos como, por exemplo, ALAS2, receptor de transferrina, ferritina entre outros. Ocorre acúmulo de ferro mitocondrial e, portanto, inadequada hemoglobinização dos eritroblastos, com consequente anemia microcítica hipocrômica e sobrecarga de ferro. Este defeito foi recentemente relatado em humanos que responderam satisfatoriamente a desferroxamina. ${ }^{18-20,24,25}$

\section{Anemia e porfirias}

\section{Protoporfiria eritropoética}

Este tipo de porfiria é causada por diminuição da atividade da ferroquelatase, enzima terminal na via de biossíntese do heme. Manifesta-se por fotossensibilidade à luz, visível logo na infância, e níveis elevados de protoporfirina IX eritrocitária. Na maioria dos casos, a herança é autossômica dominante com penetrância incompleta. É a forma mais comum de porfiria eritropoética. Anemia hemolítica microcítica hipocrômica ocorre em $20 \%$ a $60 \%$ dos casos e não há sobrecarga de ferro. Nas crianças, observa-se precocemente urina de cor rósea a marrom escuro, que mancha as fraldas devido ao excesso de excreção de porfirinas urinárias. Há também maior excreção de porfirinas fecais e formação de uro e coproporfirina eritrocitária. $\mathrm{O}$ tratamento pode ser feito com transfusão de hemácias, ácido ascórbico e vitamina $\mathrm{E}$ para redução de radicais livres e carvão (60 g, três vezes ao dia), que mostrou reduzir os níveis de porfirina na pele e no plasma. $^{26,27}$

\section{Porfiria eritropoética congênita}

Este tipo de porfiria deve-se a defeitos que alteram a função da uroporfirinogênio sintase III (UROS). A herança é autossômica recessiva para mutação no gene UROS e também 
Tabela. Características biológicas das anemias hereditárias resultantes de defeitos no metabolismo do ferro ou da síntese de heme

\begin{tabular}{|c|c|c|c|c|c|c|c|c|}
\hline & XLSA & XLSA-A & $\begin{array}{c}\text { def } \\
\text { GLRX5 }\end{array}$ & PPE & def. DMT1 & atransferrinemia & aceruloplasminemia & $\begin{array}{c}\text { def. } \\
\text { TMPRSS6 } \\
\text { (IRIDA) }\end{array}$ \\
\hline $\mathrm{MCV}$ & $60-75$ & & & $60-75$ & $45-55$ & $50-60$ & $60-75$ & $49-60$ \\
\hline Fé Sérico & $\mathrm{N}$ ou + & & & + & ++ & + & N & baixa \\
\hline TFRsat & + & & & + & ++ & + & + & baixa \\
\hline sTFR & + & & & + & ++ & $\mathrm{N}$ & $\mathrm{N}$ & + \\
\hline Sideroblastos & +++ & & & não & não & não & não & não \\
\hline PPIX & $\mathrm{Nou}-$ & $\mathrm{Nou}-$ & $\mathrm{N}$ & +++ & + & N & $\mathrm{N}$ & \\
\hline Ferro do fígado & ++ & ++ & ++ & + & +++ & +++ & ++ & $\mathrm{N}$ \\
\hline $\begin{array}{c}\text { Manifestação clinica } \\
\text { neonatal }\end{array}$ & não & não & não & $\operatorname{sim}$ & $\operatorname{sim}$ & $\operatorname{sim}$ & sim-não & não \\
\hline Efeito do Fe oral & - & - & - & - & não & não & + & refratária \\
\hline Efeito do ferro IV & - & - & - & - & não & não & + & $+/-$ \\
\hline Transmissão & $\begin{array}{l}\text { Ligado ao } \\
x\end{array}$ & $\begin{array}{c}\text { Ligado ao } \\
x\end{array}$ & AR & $D / R$ & AR & AR & $A R$ ou $A D$ & AR \\
\hline Terapia proposta & vitB6 & vitB6 & quelação & B-carot & Epo & Plasma ou apo-Tf & quelação & \\
\hline
\end{tabular}

PPE - Protoporfiria eritropoética

Tabela adaptada a partir da Tabela 2 publicada no artigo de lolascon A, De Falco L, Beaumont C. Molecular basis of inherited microcytic anemia due to defects in iron acquisition or heme synthesis. Haematologica.2009;94:395-408, doi:10.3324/haematol.13619

foi relatado um caso com mutação no fator de transcrição GATA-1, que tem herança ligada ao X e parece alterar a função da UROS . Em ambos os casos, há fotossensibilidade e anemia porque a síntese do heme está comprometida; há também hemólise, que pode confundir o diagnóstico com talassemia intermediária. Há aumento da excreção de porfirinas na urina e fezes, mas a excreção urinária de ALA e PBG são normais. Excreção das porfirinas na urina, que mancha as fraldas, é precocemente identificada. Pode haver aumento da proporfirina eritrocitária. $\mathrm{O}$ tratamento é feito como acima descrito. ${ }^{28,29}$

\section{Possíveis causas de anemia microcítica hipocrômica ainda não descritas em humanos}

\section{Hefestina}

Hefestina é uma ferro-oxidase transmembrana dependente de cobre, necessária para o transporte de ferro dos enterócitos para a circulação. Mutação neste gene foi observada num camundongo com anemia, com herança ligada ao X. Apesar da captação de ferro da dieta ser normal, a saída de ferro da membrana basolateral dos enterócitos é deficiente, resultando em deficiência de ferro e anemia microcítica hipocrômica. Até o momento não há descrição de pacientes com este defeito. . $^{1,30}$

\section{Receptor 1 de transferrina}

Este receptor é fundamental para a captação de ferro ligado à transferrina pelos tecidos. Camundongos com ausência da proteína mostram grave anemia microcítica hipocrômica com hidropisia fetal e anormalidades neurológicas difusas. Animais haploinsuficientes têm hemácias hipocrômicas e microcíticas, mas a anemia é compensada pelo aumento da produção de eritrócitos e redução de ferro tissular. ${ }^{1,31,32}$

Proteína reguladora de ferro tipo 2 (IRP2)

Esta proteína, assim como a IRP1, é sensível ao estoque de ferro citosólico e regula a transcrição de genes envolvidos no metabolismo do ferro, tais como receptor 1 de transferrina e ferritina, entre outros. Animais com perda de IRP2 desenvolvem anemia microcítica e hipocrômica e neurodegeneração associada com depleção de ferro funcional devido aos baixos níveis de receptor de transferrina e aumento da expressão de ferritina. ${ }^{1,33,34}$

\section{Antígeno epitelial transmembrana de próstata tipo 3 (STEAP3)}

Esta é uma redutase de ferro endossomal necessária para a eficiente captação de ferro ligado à transferrina e células hematopoéticas. Deficiência desta proteína foi detectada em camundongos com anemia microcítica e hipocrômica, mas até o momento não há descrição em humanos..$^{35,36}$

\section{SEC15l1}

A inativação da SEC1511 aumenta a exocitose do receptor de transferrina e consequentemente diminui a captação de ferro pelos tecidos, incluindo eritroblastos. Mutação neste gene foi descrita em camundongos. . $^{37,38}$ 
Proposta de algoritmo para escolha de genes candidatos a serem sequenciados no diagnóstico molecular da anemia microcítica genética

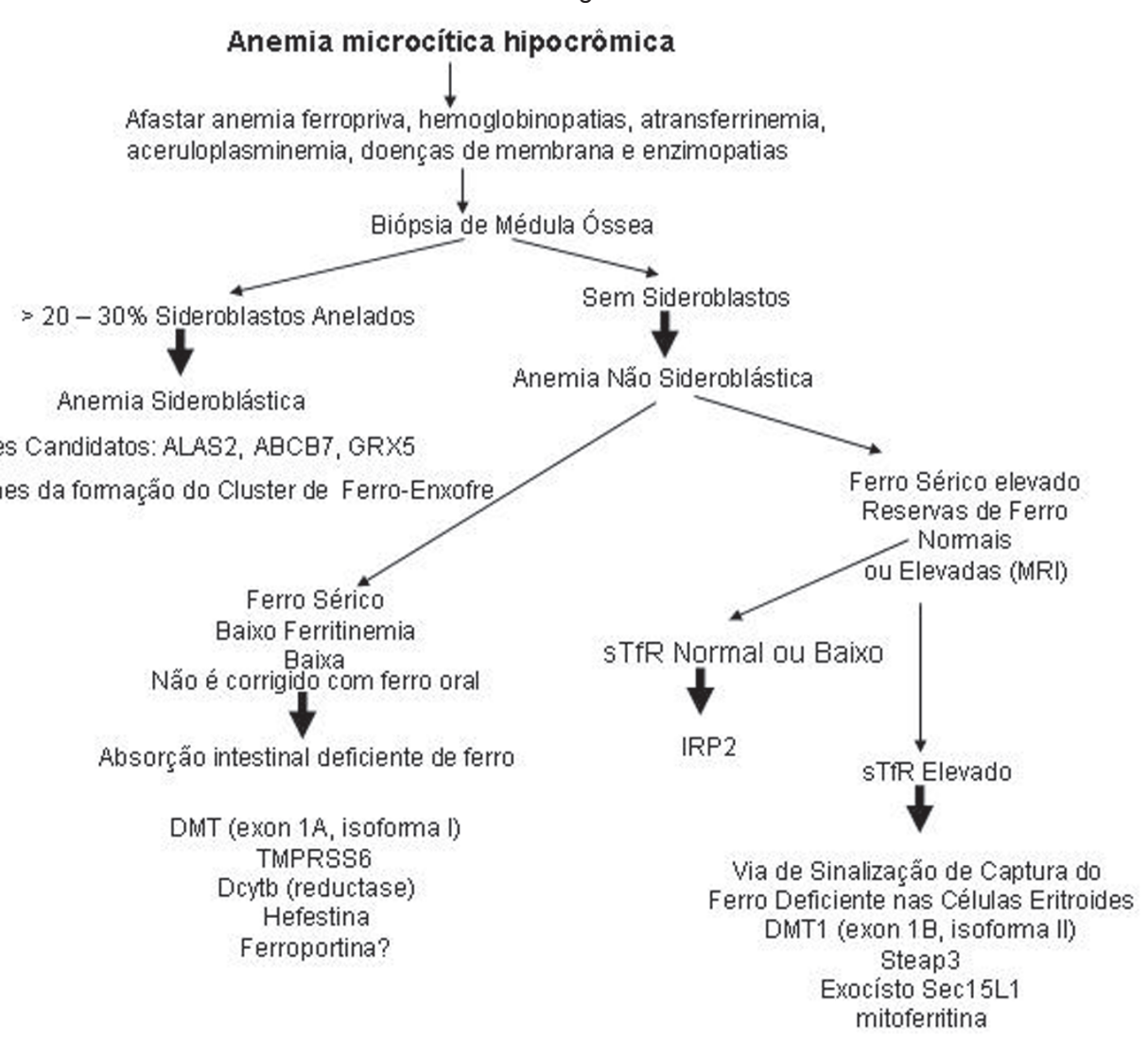

Figura adaptada a partir da Figura 3 publicada no artigo de Achille lolascon, Luigia De Falco, Carole Beaumont (Molecular basis of inherited microcytic anemia due to defects in iron acquisition or heme synthesis. Haematologica. 2009;94:395-408, doi:10.3324/haematol.13619)

\section{Conclusões}

A deficiência de ferro de causas genéticas é resultado da absorção deficiente de ferro no intestino ou da aquisição e utilização inadequada de ferro pelas células eritroides. A descoberta de novos genes envolvidos nestas deficiências, tais como GRX5, DMT1 ou TMPRSS6, somados aos genes identificados em camundongos, sugere que estas condições possam ser mais frequentes do que se supunha inicialmente. Como o diagnóstico molecular destas anemias é de fácil acesso, a dificuldade está na identificação do gene candidato adequado para ser sequenciado nestes pacientes.

\section{Abstract}

The genetic causes of iron deficiency, real or functional, occur due to defects in many proteins involved in the absorption and metabolism of iron. In this chapter we briefly describe the genetic causes of iron deficiency in the synthesis of hemoglobin, resulting in hypochromic or microcytic anemia. These alterations are rare with few descriptions in the literature. In some cases, functional iron is not available for erythroblasts to synthesis hemoglobin, or erythroblasts may be incapable of capturing iron from the circulation although iron is accumulated in tissues and mitochondrias. Many discoveries have been made over the last few years, mainly resulting from the description of human or animal models, which have elucidated the implications of the components in iron metabolism in hereditary iron deficiency involving all processes from intestinal absorption to the final inclusion into heme. Rev. Bras. Hematol. Hemoter. 2010; 32(Supl.2):99-104.

Key words: Iron deficiency; anemia, hemolytic; iron; congenital abnormalities.

\section{Referências Bibliográficas}

1. Iolascon A, De Falco L, Beaumont C. Molecular Basis of inherited microcytic anemia due to defects in iron acquisition or heme synthesis. Haematologica 2009;94(3):395-408.

2. Beutler E, Gelbaart T, Lee P, Trevino R, Fernandez MA, Fairbanks VF. Molecular characterization of a case of atransferrinemia. Blood 2000;96(13):4071-4.

3. Trombini P, Coliva T, Nemeth E, Mariani R, Ganz T, Biondi A, et al. Effects of plasma transfusion on hepcidin production in human congenital hypotransferrinemia. Haematologica 2007;92 (10): 1407-10.

4. Hayashi A, Wada Y, Suzuki T, Shimizu A. Studies on familial hypotransferrinemia: unique clinical course and molecular pathology. Am J Hum Genet 1993;53(1):201-13.

5. Harris ZL, Durley AP, Man TK, Gitlin JD. Targeted gene disruption 
reveals an essential role for ceruloplasmin in cellular iron efflux. Proc Natl Acad Sci USA. 1999;96(19):10812-7.

6. Xu X, Pin S, Gathinji M, Fuchs R, Harris ZL. Aceruloplasminemia: an inherited neurodegenerative disease with impairment of iron homeostasis. Ann N Y Acad Sci. 2004;1012:299-305.

7. Fleming MD, Trenor CC 3rd, Su MA, Foernzler D, Beier DR, Dietrich WF, et al. Microcytic anaemia mice have a mutation in Nramp2, a candidate iron transporter gene. Nat Genet. 1997; 16 (4):383-6.

8. Fleming MD, Romano MA, Su MA, Garrick LM, Garrick MD, Andrews NC. Nramp2 is mutated in the anemic Belgrade (b) rat: evidence of a role for Nramp2 in endosomal iron transport. Proc Natl Acad Sci USA. 1998;95(3):1148-53.

9. Donovan A, Brownlie A, Dorschner MO, Zhou Y, Pratt SJ, Paw BH, et al. The zebrafish mutant gene chardonnay (cdy) encodes divalent metal transporter 1 (DMT1). Blood. 2002;100(13):4655-9.

10. Mims MP, Guan Y, Pospisilova D, Priwitzerova M, Indrak K, Ponka P, et al. Identification of a human mutation of DMT1 in a patient with microcytic anemia and iron overload. Blood. 2005;105(3):1337-42.

11. Pospisilova D, Mims MP, Nemeth E, Ganz T, Prchal JT. DMT1 mutation: response of anemia to darbepoetin administration and implications for iron homeostasis. Blood. 2006;108(1):404-5.

12. Du X, She E, Gelbart T, Truksa J, Lee P, Xia Y, et al. The serine protease TMPRSS6 is required to sense iron deficiency. Science 2008;320(5879):1088-92.

13. Finberg KE, Heeney MM, Campagna DR, Aydinok Y, Pearson HA, Hartman KR, et al. Mutations in TMPRSS6 cause iron-refractory iron deficiency anemia (IRIDA). Nat Genet. 2008;40(5):569-71.

14. Silvestri L, Guillem F, Pagani A, Nai A, Oudin C, Silva M, et al. Molecular mechanisms of the defective hepcidin inhibition in TMPRSS6 mutations associated with iron-refractory iron deficiency anemia. Blood. 2009;113(22):5605-8.

15. Camaschella C \& Poggiali E. Towards explaining "unexplained hyperferritinemia". Haematologica. 2009;94(3):307-9.

16. De Domenico I, Ward DM, Nemeth E, Vaughn MB, Musci G, Ganz $\mathrm{T}$, et al. The molecular basis of ferroportin-linked hemochromatosis. Proc Natl Acad Sci USA. 2005;102(25):8955-60.

17. Sham RL, Phatak PD, West C, Lee P, Andrews C, Beutler E. Autosomal dominant hereditary hemochromatosis associated with a novel ferroportin mutation and unique clinical features. Blood Cells Mol Dis. 2005;34(2):157-61.

18. Bottomley SS. Congenital sideroblastic anemias. Curr Hematol Rep. 2006;5(1):41-9

19. Bergmann AK, Campagna DR, McLoughlin EM, Agarwal S, Fleming $\mathrm{MD}$, Bottomley SS, et al. Systematic molecular genetic analysis of congenital sideroblastic anemia: evidence for genetic heterogeneity and identification of novel mutations. Pediatr Blood Cancer 2010;54(2):273-8.

20. Guernsey DL, Jiang H, Campagna DR, Evans SC, Ferguson M, Kellogg MD, et al. Mutations in mitochondrial carrier family gene SLC25A38 cause nonsyndromic autosomal recessive congenital sideroblastic anemia. Nat Genet. 2009;41(6):651-3.

21. Furuyama K, Fujita H, Nagai T, Yomogida K, Munakata H, Kondo $\mathrm{M}$, et al. Pyridoxine refractory $\mathrm{X}$-linked sideroblastic anemia caused by a point mutation in the erythroid 5 -aminolevulinate synthase gene. Blood. 1997;90(2):822-30.

22. Furuyama K, Sassa S. Interaction between succinyl CoA synthetase and the heme-biosynthetic enzyme ALAS-E is disrupted in sideroblastic anemia. J Clin Invest. 2000;105(6):757-64.

23. Bekri S, Kispal G, Lange H, Fitzsimons E, Tolmie J, Lill R, et al. Human $\mathrm{ABC} 7$ transporter: gene structure and mutation causing $\mathrm{X}$ linked sideroblastic anemia with ataxia with disruption of cytosolic iron-sulfur protein maturation. Blood. 2000;96(9):3256-64.
24. Wingert RA, Galloway JL, Barut B, Foott H, Fraenkel P, Axe JL, et al. Deficiency of glutaredoxin 5 revels Fe-S clusters are required for vertebrate haem synthesis. Nature. 2005;436(7053):1035-39.

25. Camaschella C, Campanella A, De Falco L, Boschetto L, Merlini $\mathrm{R}$, Silvestri L, et al. The human counterpart of zebrafish shiraz shows sideroblastic-like microcytic anemia and iron overload. Blood 2007;110(4):1353-8.

26. Holme SA, Worwood M, Anstey AV, Elder GH, Badminton MN. Erythropoiesis and iron metabolism in dominant erythropoietic protoporphyria. Blood. 2007;110(12):4108-10.

27. Lyoumi S, Bitbol M, Andrieu V, Henin D, Robert E, Schmitt C, et al. Increased plasma transferrin, altered body iron distribution, and microcytic hypochromic anemia in ferrochelatase-deficient mice. Blood. 2007;109(2):811-8.

28. Phillips JD, Steensma DP, Pulsipher MA, Spangrude GJ, Kushner JP. Congenital erythropoietic porphyria due to a mutation in GATA1: the first trans-acting mutation causative for a human porphyria. Blood. 2007;109(6):2618-21.

29. Solis C, Aizencang GI, Astrin KH, Bishop DF, Desnick RJ. Uroporphyrinogen III synthase erythroid promoter mutations in adjacent GATA1 and CP2 elements cause congenital erythropoietic porphyria. J Clin Invest. 2001;107(6):753-62.

30. Vulpe CD, Kuo YM, Murphy TL, Cowley L, Askwith C, Libina N, et al. Hephaestin, a ceruloplasmin homologue implicated in intestinal iron transport, is defective in the sla mouse. Nat Genet. 1999;21(2):195-9.

31. Levy JE, Jin O, Fujiwara Y, Kuo F, Andrews NC.Transferrin receptor is necessary for development of erythrocytes and the nervous system. Nat Genet. 1999;21(4):396-9.

32. Zhu BM, McLaughlin SK, Na R, Liu J, Cui Y, Martin C, et al. Hematopoietic-specific Stat5-null mice display microcytic hypochromic anemia associated with reduced transferrin receptor gene expression. Blood. 2008;112(5):2071-80.

33. Galy B, Ferring D, Minana B, Bell O, Janser HG, Muckenthaler M, et al. Altered body iron distribution and microcytosis in mice deficient in iron regulatory protein 2 (IRP2). Blood. 2005;106(7):2580-9.

34. Cooperman SS, Meyron-Holtz EG, Olivierre-Wilson H, Ghosh MC, McConnell JP, Rouault TA. Microcytic anemia, erythropoietic protoporphyria, and neurodegeneration in mice with targeted deletion of iron-regulatory protein 2. Blood. 2005;106(3):1084-91.

35. Ohgami RS, Campagna DR, Greer EL, Antiochos B, McDonald A, Chen $\mathrm{J}$, et al. Identification of a ferrireductase required for efficient transferrin-dependent iron uptake in erythroid cells. Nat Genet. 2005;37(11):1264-9.

36. Lambe T, Simpson RJ, Dawson S, Bouriez-Jones T, Crockford TL, Lepherd M, et al. Identification of a Steap3 endosomal targeting motif essential for normal iron metabolism. Blood. 2009;113 (8):1805-8

37. Garrick MD, Garrick LM. Loss of rapid transferrin receptor recycling due to a mutation in Sec1511 in hbd mice. Biochim Biophys Acta. 2007;1773(2):105-8.

38. Lim JE, Jin O, Bennett C, Morgan K, Wang F, Trenor CC 3rd, et al. A mutation in Sec1511 causes anemia in hemoglobin deficit (hbd) mice. Nat Genet. 2005;37(11):1270-3.

O tema foi sugerido e avaliado pelo coeditor deste fascículo educativo, Rodolfo Delfini Cançado, e pelo board interno da RBHH, e publicado após a concordância do editor, Milton Artur Ruiz.

Conflito de interesse: sem conflito de interesse

Recebido: 22/12/2009

Aceito: $16 / 01 / 2010$ 